\title{
Gestão participativa: \\ estratégia de consolidação do sistema único de saúde
}

\author{
Participative management: \\ unified health system consolidation strategy
}

\author{
Edirlei Machado dos Santos ${ }^{1}$
}

Resumo

$\mathrm{Na}$ atual conjuntura das políticas de saúde no Brasil e da evolução do Sistema Único de Saúde (SUS), tem sido bastante evidenciada a participação da sociedade na avaliação e implementação de propostas que garantam a consolidação do SUS em todos os níveis, tipos de serviços e esferas de governo. $\mathrm{O}$ artigo buscou conceitualizar e caracterizar a gestão participativa, por meio de referenciais teóricos que tomam o controle social como estratégia da participação no processo de consolidação do Sistema Único de Saúde.

Palavras-chave: Participação Comunitária. Reforma dos Serviços de Saúde.

\begin{abstract}
In the current conjuncture of health policies in Brazil and the evolution of the Unified Health System (UHS), it has been emphasized the society's participation in the evaluation and implementation of proposals that ensure UHS consolidation at all levels, types of services and government spheres. The purpose of this article was to conceptualize and characterize the participative management, by means of a theoretical framework that considers social control as participation strategy in the UHS consolidation process.

Key words: Community Participation. Health System Reform.
\end{abstract}

\footnotetext{
1 Enfermeiro, Especialista em Saúde Pública e Auditoria de Enfermagem, Mestrando em Enfermagem pela Universidade Estadual de Campinas - UNICAMP/SP. Docente do Curso de Graduação em Enfermagem da Fundação Municipal de Educação e Cultura de Santa Fé do Sul (FUNEC)/SP. E-mail: edirleimachado@hotmail.com
} 


\section{Introdução}

Houve várias mudanças ao longo de toda história das políticas de saúde no Brasil. Durante essa trajetória, a participação da população no estabelecimento, implementação e avaliação dos serviços de saúde não fazia parte da práxis dos serviços de assistência à saúde.

Nesse cenário, o atendimento à saúde da população sempre apresentou uma situação de iniqüidade e dificuldade de acesso pela maior parte da população aos serviços de saúde, situação esta, determinada entre outras, pelos contextos social, econômico, político e ideológico em cada período percorrido.

No atual cenário, temos um sistema de saúde pautado pelos princípios da universalidade, eqüidade e integralidade que foram essenciais para mudar o panorama histórico dos serviços de saúde no Brasil. Anteriormente à criação do Sistema Único de Saúde (SUS), para Baptista (2005), a saúde não se caracterizava como um direito de todos, muito menos como dever do Estado.

A criação do SUS, em 1988, por meio da Constituição Federal, e sua regulamentação por meio da Lei Orgânica da Saúde (leis 8.080 e $8.142 / 1990$ ), proporcionaram à população brasileira uma participação nas decisões de implementação e aplicação das políticas públicas de saúde. Essa participação dá-se pela presença da sociedade por meio dos Conselhos de Saúde e das Conferências de Saúde, nas três esferas de representação do SUS (municipal, estadual e federal).

A participação dos usuários dos serviços de saúde permitiu a implementação do controle social determinado pelo processo de democratização dos serviços de saúde, salientando que a participação da população na efetivação e (re) construção dos serviços de saúde até então era nula.

Segundo Costa e Noronha (2003), o controle social constitui uma forma de participação da sociedade nas decisões e avaliações para (re) estruturação dos serviços de saúde no Brasil e está inerentemente relacionado ao processo de descentralização em conseqüência da aproximação territorial entre usuários e gestores. Desse modo, toda ação controladora da sociedade sobre o Estado, por meio de instrumentos próprios específicos em relação ao SUS, está inserida no contexto que se denomina controle social.

\section{Objetivo}

Buscar por meio da literatura referenciais teóricos capazes de conceituar e caracterizar a gestão participativa no âmbito do SUS.

\section{Metodologia}

Este estudo caracteriza-se por uma pesquisa bibliográfica. Segundo Gil (2002), esta é desenvolvida com base em material já elaborado, constituído essencialmente de livros e artigos científicos. A principal vantagem da pesquisa bibliográfica consiste em proporcionar ao investigador a cobertura de uma variedade de fenômenos muito mais ampla.

A busca de referenciais para elaboração deste estudo foi realizada nas bases de dados LILACS (Literatura Latino Americana e do Caribe em Ciências da Saúde), BDENF (Base de Dados da Enfermagem), SciELO (Scientific Electronic Library On line), DEDALUS da Universidade de São Paulo e ACERVUS da Universidade Estadual de Campinas.

Foram também utilizados artigos científicos e/ou outras publicações que chegaram ao conhecimento do autor e discutiam a temática a ser estudada.

O levantamento de dados foi realizado entre os meses de setembro e dezembro de 2007, utilizando o descritor gestão participativa. Foram encontradas 108 referências na base de dados LILACS, 43 na base SciELO e dois na base BDENF. Após a leitura dos resumos, foram selecionados 8 artigos que tomavam a gestão participativa no âmbito do SUS. 
Também foi feito um levantamento acerca da educação em saúde, enquanto instrumento necessário para a construção da gestão participativa enquanto estratégia para concretização do SUS.

Caracterizando o controle social e a gestão participativa

O contexto mencionado e subsídios fornecidos pela prática assistencial, enquanto enfermeiro nos serviços de saúde pública, (especificamente na atenção primária à saúde), levou-se a perceber, empiricamente uma forma de participação popular incoerente com o que se determinava pelo atual sistema de saúde brasileiro. Isso gerou em mim uma inquietação, fazendo com que buscasse por meio da literatura conceitos e a importância da participação dos usuários no processo de consolidação do SUS.

De acordo com Brasil (2004, p. 101),

o controle social da Política de Saúde do SUS é um dos princípios fundamentais da reforma Sanitária Brasileira e uma importante inovação garantida pela Constituição. O controle social e a gestão participativa no SUS contribuem para a ampliação da cidadania, identificando o usuário como membro de uma comunidade organizada com direitos e deveres, diferente de uma mera visão de consumidor de bens e serviços.

O Ministério da Saúde instituiu a gestão participativa como meio de efetiva participação da comunidade nas discussões das políticas de saúde.

Para Cordeiro e Ribeiro (2006), o processo de gestão, atualmente, envolve uma série de atividades mais abrangente e diversificada que no passado. Assim, "a gestão participativa é o modelo de gestão que mais se adapta ao novo homem da sociedade do conhecimento, indivíduo este, que tem como característica marcante o inconformismo diante de respostas vagas e atitudes sem sentido".
Com isso, Brasil (2006) afirma que a gestão estratégica e participativa caracteriza-se como um conjunto de atividades voltadas ao aprimoramento da gestão do SUS, buscando maior eficácia, eficiência e efetividade, por meio de ações que incluem, entre outros, o apoio ao controle social, a educação popular e a mobilização social.

No Brasil, as conquistas populares têm apresentado uma mobilização social em defesa do direito à saúde. Nas conferências nacionais de saúde, têm-se discutido como indispensáveis, a implementação e o fortalecimento dos mecanismos de controle social existentes (BRASIL, 2006).

Misoczky (2003) aponta que o controle social tem sido tratado com enfoque estruturalista e normativo e a gestão participativa deixada ao esquecimento, a não ser pela prática e reflexão de alguns poucos gestores e acadêmicos.

Gestão participativa é definida por Rocha (2003 apud MISOCZKY, 2003) como a orquestração de um conjunto de políticas geradas em conjunto com a sociedade, sendo participativa por permitir a construção de ações planejadas por executores e usuários; porque trabalha com recuos e avanços decididos pelos próprios protagonistas do processo; por proporcionar aos atores o exercício da aprendizagem; por entender que a responsabilidade para ser solidária, deve ser, em princípio, assimilada, compreendida e internalizada.

Considerando o processo participativo, Oliveira (2003) aponta que este é muito recente, em conseqüência das ações ditatoriais presentes em vários momentos sócio-políticos nacionais.

Segundo Jacobi (2000, p. 27),

o conceito de participação está permeado de contradições, não só pela sua relação com o poder público, mas também pela sua amplitude conceitual. [...] nem sempre são claras as diferenças entre participação citadina, participação social ou participação comunitária ou, ainda, participação popular. 
O processo participativo manifesta-se, de maneira mais evidente, por meio de movimentos sociais, diretamente na sociedade civil ou por meio de órgãos colegiados - os conselhos sociais e vai ganhando espaço político e administrativo nas instituições do aparelho estatal (OLIVEIRA, 2003).

É necessário, de acordo com Brasil (2004), qualificar o controle social do SUS envolvendo o fortalecimento e estruturação dos Conselhos de Saúde. Busca-se, assim, criar simultaneamente mecanismos eficientes de escuta do cidadão/ usuário e da população em geral, reformulando o conceito e a dinâmica das ouvidorias do SUS, permitindo uma maior publicidade e transparência das prestações de contas e de relatórios de gestão. Todos esses fatores contribuem para a qualificação da administração pública, ampliando o seu comprometimento com a participação popular e a gestão participativa.

Oliveira (2003), em sua tese de doutorado, procura retratar a trajetória da participação social no Brasil, desde a década de 60 até a instituição dos Conselhos Sociais, evidenciando que, na Saúde Pública, esta participação foi legalizada pela Lei $8.142 / 90$, na perspectiva do Controle Social.

Nesse processo de construção da cidadania e participação social, a prática educativa emana como possibilidade de construção de um conhecimento emancipatório, em que as pessoas possam ser, de fato, participantes na concretização dos serviços e políticas de saúde.

\section{A educação como conduta humana}

Segundo Brandão (2006), ninguém está separado da educação, qualquer que seja o local, estamos em contato com ela, seja para aprender, para ensinar ou para aprender-ensinar.

Ele ainda aponta que a educação é uma fração do modo de vida dos grupos sociais que a criam e recriam, entre tantas outras invenções de sua cultura, em sua sociedade. Quando um povo alcança um estágio complexo de organização da sua sociedade e de sua cultura, quando enfrenta entre outras a divisão social do trabalho e, portanto, do poder, ele começa a viver e pensar como problema as formas e os processos de transmissão do saber.

[...] A educação aparece sempre que surgem formas sociais de condução e controle da aventura de ensinar-e-aprender. $\mathrm{O}$ ensino formal é o momento em que a educação se sujeita à pedagogia (a teoria da educação), cria situações próprias para o seu exercício, produz os seus métodos, estabelece suas regras e tempos, e constitui executores especializados. [...] (BRANDÃO, 2006. p. 26).

Assim, vivemos dentro de uma ordem social regida por um sistema amplo e muito complexo de relações de produção entre tipos de meios e produtores, que se denominam de modo de produção capitalista. Nesse contexto, não podemos deixar de compreender, dentre outros, a educação num cenário de tipos de trocas regidos pela dialética entre o capital e o trabalho (BRANDÃO, 2006).

Esta relação entre divisão social e educação é fator gerador do processo denominado por Freire (2005) pedagogia do oprimido. A pedagogia do oprimido evidencia a forma como esse processo de divisão de classes (entre a classe dominante e a classe trabalhadora) se realiza, na prática: a primeira impõe sua ideologia à segunda, e faz com que esta acredite e entenda que deve, por sua própria localização no extrato social, viver na opressão.

Dentro desse contexto, é fato que cada comunidade apresenta aspectos culturais e formas diversificadas de pensar, ensinar e aprender, a divisão social de grupos, o que contribui para uma sociedade heterogênea, determinante da separação de classes.

Assim, Lima e Baptista (1997), em seu estudo com moradores e participantes de um Comitê Comunitário e enfermeiras, verificaram que, com relação aos primeiros, ficou evidente, manifestações 
de conformismo e resistência, em relação às diferentes visões de mundo das pessoas que constituem os grupos de trabalho do Comitê. Desse modo, é possível perceber que a classe trabalhadora, principal usuária dos serviços públicos de saúde, acredita que essa é a realidade e que nada pode fazer para mudar.

Isso demonstra a necessidade de um trabalho de caráter educativo, como estratégia para $o$ desenvolvimento na população de um conhecimento, cuja prática resulte no processo de exercício de cidadania. Desse modo, a gestão participativa se torna essencial enquanto forma de consolidação do SUS.

Dessarte, esse processo de controle social e desempenho da cidadania buscam como cerne as práticas educativas, considerando esta como estratégia de formação e mudanças de paradigmas.

\section{As práticas pedagógicas em educação}

Freire (2005) apresenta as opções pedagógicas, empregadas para o desenvolvimento de ações educativas.

Uma delas o autor denomina de pedagogia da transmissão ("educação bancária"), e nela o "saber" é uma doação, na relação entre aqueles que se julgam sábios e os que julgam nada saber. Essa situação é explicitamente calcada na ideologia de opressão (FREIRE, 2005).

Na concepção “bancária”, segundo Freire (2005), é característico o ato de depositar, de transferir, de transmitir valores e conhecimentos, refletindo com isso a sociedade opressora.

Com relação à educação bancária, Freire (2005, p. 68), coloca que:

a) o educador é o que educa; os educandos, os que são educados;

b) o educador é o que sabe; os educandos os que não sabem; c) o educador é o que pensa; os educandos os pensados;

d) o educador é o que diz a palavra; os educandos, os que a escutam docilmente;

e) o educador é o que disciplina; os educandos os disciplinados;

f) o educador é o que opta e prescreve sua opção; os educandos, os que seguem a prescrição;

g) o educador é o que atua; os educandos, os que têm a ilusão de que atuam, na atuação do educador;

h) o educador escolhe o conteúdo programático; os educandos, jamais ouvidos nesta escolha, se acomodam a ele;

i) o educador identifica a autoridade do saber com sua autoridade funcional, que opõe antagonicamente à liberdade dos educandos; estes devem adaptar-se às determinações daquele;

j) o educador, finalmente, é o sujeito do processo; os educandos, meros objetos.

Desse modo, a "educação bancária" anula o poder criador dos educandos ou minimiza, não desenvolvendo na mesma sua capacidade crítica de satisfação dos interesses opressores (FREIRE, 2005).

Freire (2005) aponta outro método pedagógico de fazer a educação e a relação entre educadoreducando; a pedagogia problematizadora ou libertadora. A utilização deste método propõe, ao contrário da educação "bancária" a libertação, e nela não há domínio por parte do educador com relação ao educando, mas um processo integrativo, em que o conhecimento não é despejado para o educando, mas que vai sendo socialmente construído.

Transportando essas colocações de Freire, da área educacional para os serviços de saúde coletiva, é possível perceber que, na prática dos serviços de saúde coletiva, é explícita a utilização de forma exacerbada do método "bancário" de se desenvolver a educação em saúde, pois ocorre que, muitas vezes, não se parte de pressupostos dos usuários para a construção social do conhecimento. 


\section{Considerações finais}

O cenário atual dos serviços de saúde pública permite-nos observar que o controle social é fundamental para implementar ou intensificar as ações de gestão participativa.

Sabemos que o SUS não é um sistema de saúde concluído, mas a participação dos usuários nesse sistema, enquanto cidadãos, é essencial para garantia de acesso de forma equânime e integral aos serviços de saúde.

Nesse processo, cabe, aqui, uma reflexão e um re(pensar) em proporcionar aos cidadãos o exercício de sua cidadania para a concretização de um sistema de saúde que possa, mesmo com suas debilidades, atender aos anseios de saúde da população.

Assim, é evidente a utilização da educação popular como instrumento de estímulo da participação da população no cerne dos serviços de saúde. No entanto, para Vasconcelos (2004), quase todos os gestores, embora enfatizem em seus discursos a necessidade da ação educativa e da promoção da saúde, pouco se tem investido em uma política consistente, que permita a difusão do saber da educação popular como meio de garantir a participação dos usuários no processo de gestão dos serviços de saúde.

Contudo, espera-se que a co-participação entre gestores, profissionais e usuários seja algo mais prático e que ela possa gerar discussões, avaliações e a implementação de serviços de saúde consistentes e adequados às necessidades de saúde da população brasileira, seja nas ações de prevenção, promoção ou recuperação, seja nos níveis primário, secundário e terciário de assistência, seja nas esferas municipal, estadual ou federal.

Destarte, poderemos efetivamente difundir a prática da gestão participativa por meio do controle social e alcançar plenamente a concretização do SUS.

\section{Referências}

BAPTISTA, T. W. F. O direito à saúde no Brasil: sobre como chegamos ao Sistema Único de Saúde e o que esperamos dele. In: Textos de apoio: políticas de saúde. Rio de Janeiro: Fiocruz, 2005. Cap. 1, p. 11-41.

BRANDÃO, C. R. O que é educação. São Paulo: Brasiliense, 2006.

BRASIL. Ministério da Saúde. Controle social e gestão participativa. In: CONFERÊNCIA NACIONAL DE SAÚDE: RELATÓRIO FINAL, 12., 2004. Brasília. Anais...Brasília: Ministério da Saúde, 2004. p. 99-111.

BRASIL. Ministério da Saúde. Política nacional de gestão estratégica e participativa no SUS: participa SUS. Brasília: Ministério da Saúde, 2006.

CORDEIRO, J. V. B. M.; RIBEIRO, R. V. Gestão da empresa. Disponível em: <http://www.fae.edu/ publicacoes/pdf/empresarial/1.pdf $>$. Acesso em: $14 \mathrm{de}$ nov. 2006

COSTA, A. M.; NORONHA, J. C. Controle social na saúde: construindo a gestão participativa. Saúde em Debate, Rio de Janeiro, v. 27, n. 65, p. 358-363, set./dez. 2003.

FREIRE, P. Pedagogia do oprimido. Rio de Janeiro: Paz e Terra, 2005, $213 \mathrm{p}$.

GIL, A. C. Como classificar as pesquisas? In: GIL, A. C. Como elaborar projetos de pesquisa. 4. ed. São Paulo: Atlas, 2002. Cap. 4, p. 41-58.

JACOBI, P. Políticas sociais e ampliação da cidadania. Rio de Janeiro: FGV, 2000.

LIMA, C. B.; BAPTISTA, S. S. Educação e saúde visando à cidadania: práxis grupal de enfermeiras. Revista Brasileira de Enfermagem, Brasília, v. 50, n. 4, p. 469-476, out./dez., 1997.

MISOCZKY, M. C. Gestão participativa em saúde: potencialidades e desafios para o aprofundamento da democracia. Saúde em Debate, Rio de Janeiro, v. 27, n. 65, p. 336-347, set./dez. 2003.

OLIVEIRA, M. L. Controle social e gestão participativa em saúde pública: a experiência de conselhos gestores de unidades de saúde do município de Campo Grande/MS1994/2002. 2003. Tese (Doutorado em Saúde Pública) Universidade de São Paulo, São Paulo.

VASCONCELOS, E. M. Educação popular: de uma prática alternativa a uma estratégia de gestão participativa das políticas de saúde. Physis: Revista de Saúde Coletiva, Rio de Janeiro, v. 14, n. 1, p. 67-83, 2004. 